The effectiveness of using educational robot in the computer course in the development of scientific thinking skills among first year secondary students

\author{
Al-Mohammadi, Najwa $\measuredangle$ \\ University of Jeddah, Saudi Arabia (dr_najwa@hotmail.com)
}

Received: 28 December 2016 Available Online: 6 April 2017
Revised: 27 March 2017 DOI: $10.5861 /$ ijrset.2017.1734

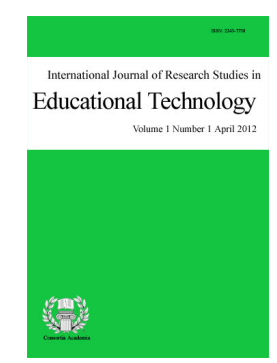

ISSN: $2243-7738$ Online ISSN: 2243-7746

OPEN ACCESS

\title{
Abstract
}

The present study aimed at assessing the effectiveness of using the educational Robot in the Computer Course in the development of scientific thinking skills among first year secondary students. The researcher used the quasi-experimental design with two groups: experimental and control with 30 students each. The sample was selected purposively from the 4th Secondary School in Jeddah City. The study tool consisted of a testing scale of the unit "Digital Control and the Robot" to assess scientific thinking skills for the pre and the post tests after studying the unit for both groups. The statistical analysis of results showed the following: there were statistically significant differences between students' achievement in the pre and the post tests in the scientific thinking skills. This suggests that there is some development in scientific thinking skills in favor of the post test of the experimental group. The calculated $(\mathrm{t})$ value was (6.97). The researcher recommended; first, curriculum designers should use the educational Robot in curricula design in order to create integrity between different fields. Second, decision makers should design training courses for teachers in the building and designing of Robot programming and to assess the effectiveness of using the educational Robot in the development of the skills of students with Special Needs.

Keywords: scientific thinking skills; computer courses; educational robot; quasi- experimental; Jeddah 


\section{The effectiveness of using educational robot in the computer course in the development of scientific thinking skills among first year secondary students}

\section{Introduction}

Recently, the world has witnessed knowledge and technical development in all fields, which has had a prominent effect in producing radical changes in the cognitive environment and educational practices of educational systems. As a result, learning has shifted from teacher-centered learning towards student-center learning. The student has an effective role in the educational process through higher thinking skills activities, which enable him to process, criticize, and analyze information that help to solve his daily problems, and he acquires lifelong autonomous learning skills in the process. Thus, choosing the right educational aid that enables students to solve problems, make decisions, and be autonomous learners, has become a must in order to achieve objectives drawn by students and guided by teachers. The educational robot is one of the modern fields that rapidly spread in all educational fields throughout the world. The robot is a tool that does tasks which fill our lives, and does lots of impossible tasks for man. In this respect, building and designing the robot starts with simple instructions learned by students and serves as an approach to learn basic principals in science through application. Now we have the robot as an educational practical aid that opens unlimited horizons for a student to think, design, apply and employ scientific principals he knows and searches for when striving to reach his goal. Using an educational robot can benefit the educational process in two ways. The first is to provide a set of ready educational robots for students to deal with inside their classrooms. The second is to set up labs for educational robots inside schools, in order to enable students to learn how to build robots. This is achieved by undergoing different educational processes for building robots, which are capable of doing certain tasks, and then initiating the path of programing them (Yassen, 2014). Although the two methods are important, the second method is the best in this field. It provides labs for robots in schools and integrates with the first method; thereby achieving best results for students because, often, the students need to work in teams to achieve certain enhancements for the robot and consequently, it develops communication skills between students. Teaching robot has been accredited in many schools all over the world, as it was favored by students, teachers and parents. Robot science provides an encouraging environment based on autonomous learning, handcraft, integrating sciences and learning through experimentation, deduction, observation, and offering creative solutions' suggestions.

\subsection{Study Problem}

With the advent of directives by the Saudi ministry of Education regarding developing curriculum and techniques according to the requirements of the 21st Century, which is considered one of King Abdulaziz' University (Jeddah, Saudi Arabia) goals to develop education through the enormous use of both technical devices and electronic games, the researcher - based on the pilot study- found that educational robots are a fertile field for developing Scientific thinking skills. Due to the scarcity of Arabic Studies in that field, the researcher conducted this particular study. The focus of this study is to measure the effectiveness of using an educational robot as a computer course, in developing Scientific thinking skills for first Grade secondary school students.

Questions of the Study - What is the effect of using educational robot as a computer course in developing Scientific thinking skills for first Grade secondary school students?

Hypothesis of the Study - The current study tests the following hypothesis: There are no statistical differences at the $.05 \alpha$ level, between the mean scores of the Experimental and Control groups in the post test of Scientific thinking skills, after controlling the pretest.

Objectives of the Study - The current study aims to show the effectiveness of using the educational robot as a computer course, in developing Scientific thinking skills for the first-Grade secondary school students. 
Effectiveness of educational robot in computer course in the development of scientific thinking skills

Significance of the Study - It aims to use technologies and modern aids of educational process to stimulate 21 st-century skills, including decentralizing scientific thinking for students. It intends to guide officials in the ministry of education on the importance of using an educational robot in the educational process. Furthermore, it will add new Arabic study to literature related to the educational robot and scientific thinking.

\subsection{Definition of Terms}

Effectiveness - Zayton (2005) defined effectiveness as: "the ability to achieve goals" (p. 54). Attia (2008) on the other hand, defined effectiveness as goal's achievement, and the ability to achieve is the measurement by which we know the performance of the teacher and the student as Partners in the teaching and learning process. (p. 61). Operationally, in this study, effectiveness is the expected effect of using robots in Scientific thinking skills valuably, and is measured by the mean scores of the experimental group students.

Educational Robot - Educational robot is defined by the American Institute of Robots (RIA) as a mechanically programed machine that performs repetitive tasks, and has the ability to work in conditions and places that is hard for man to function in. Operationally, in this study, robot is an educational aid that simulates human mental skills such as thinking, designing and implementation, to achieve a certain goal.

\section{Review of literature}

\subsection{Educational robotics}

Educational robotics has certain characteristics and advantages that help them to spread throughout educational environments; from primary stages, up to college level, as they encourage thinking and creativity. Many educators believe that educational robots are considered important educational programs in all learning stages. Learning through designing, building and programming the robot helps in acquiring knowledge and skills of Computer science and electronic engineering, and that is considered the first requirement for countries to be industrially developed. In addition, teaching through the use of robots helps in developing higher thinking levels, problem solving, cooperative work, and competitions (Verner \& Hershko, 2003). The following section discusses the concept of an Educational robot, its objectives and its importance in the educational process.

\subsection{The concept of education robotics}

The Educational robotics (robot) is a mechanical machine capable of doing pre-programmed tasks. These tasks could be hard or dangerous, such as searching for mines, outer space and cleaning nuclear wastes (Yassen, 2005). The Massachusetts Institute of Technology (MIT) stated that controlling a physical electronic device helps students in finding new patterns for learning. As a result, the researchers developed new techniques to use small moving robots as aids in primary and high schools. (Rusk, Berg, \& Resnick, 2008)

\subsection{Importance of the educational robot}

Verner and Hershko, in their study, pointed out the importance of using educational programs that are based on robot skills. They stated that concentration on unlimited robot programs is a strong motivation for students' creativity and ability to be autonomous learners, and consequently they will also acquire scientific research skills. In addition, creating an atmosphere of competitiveness and cooperation between students in groups helps in deeply strengthening their professional, social and educational relationship, and increases communication skills and fosters the team spirit. The use of an educational robot aids students to enroll in the National Educational Olympics for robots, and develops a sense of working with others (Verner \& Hershko, 2003).

Domestically, a country like Jordan is on a higher level with its educational institutions and programs, related to the use of robots and modern technologies, because of direct support by the Queen Rania center and 
Ministry of education since 2006 (Al-Habahba, 2010). Al-Habahba (2010), in her study on the importance of educational robotics' programs and projects, mentioned that using educational robotics enhances students' leadership spirit and responsibility in the team. In addition, it develops hand working skills through direct practical application of tools and parts to build and design the body of the robot. Furthermore, it helps to learn the fundamentals of programming.

Using educational robotics also helps in encouraging project based learning strategies, as the idea of a robot is based on projects such as, programming a car to move on a certain course, designing a robot that does certain tasks, and building a robot that is capable of doing lab experiments etc. Building and designing an educational robot is based on developing higher thinking skills like critical thinking, creative thinking, multiple intelligence, problem-solving skills, mental skills, and scientific research, which helps students to be creative in designing and programming. Furthermore, the integration process with other sciences such as Physics, Mathematics and Computers, raises students' awareness of how to integrate Theoretical sciences, Humanities, and Practical Production sciences in light of knowledge evolution. In addition, using a robot helps students to be autonomous learners and encourages student-centered learning. This is achieved by providing students with open projects and letting them solve problems, using their understanding and application of designing and programing techniques.

Using educational robot encourages cooperative learning, as the student cannot work alone. Instead, they work in teams of three to five to produce a particular robot. In each educational session, the teacher gives the students a specific concept and allows them work in groups to achieve the objective, and to apply the concept to build a robot capable of doing the requested tasks. At this stage, the teacher is a guide and a manager for the educational process and students do most of the work. In each educational session, students apply projects or a part of a project with preset objectives set by the teacher. During the application, students learn a set of concepts and theories in order to practically apply them, making best use of all information, knowledge and skills that they have. Every project of educational robotics consists of several steps, the most important being, designing a robot body and programming the processor to execute certain commands. All instructions are done in a healthy, educational, fully- equipped environment, which helps students to reach their goals and achieve the objectives of the session.

Verner and Hershko (2003) conducted a study about designing a special robot to put out fires and to assess learning outcomes. The study aimed at teaching programming and designing for students. Results revealed six stages for the process of designing and producing a mechanical system; ideal of the project, specifications of the project, concept of designing, designing details and production, application and evaluation. Results also revealed the documentation of students' evaluation which was collected from three resources; group portfolio, trainer observations, and the project or competition questionnaire. Results indicated the effectiveness of each student in robot programs with regard to building, designing, programming and attitude towards technology in general (Verner \& Hershko, 2003).

\subsection{Educational robotics and the $21^{\text {st }}$ century}

The $21^{\text {st }}$ century has witnessed massive development in information and electronic technology. As a result, robotic technology and its uses have developed into a globally promising industry, and have become a standard for the power of the country, especially if it provided versatile developed technology for use of the robot. Robot technology could be used in all military and civilian fields, in a form that enables that technology to self-adapt with all surrounding circumstances. The real emergence of robotics began in the mid-twentieth century, although it was used before that time in the industry of self-motion machines, which considered fundamental physics technology. In the past, robots were one function type, as they only performed one function, but in the $21^{\text {st }}$ century and with massive development in technology, information, computers, applied mathematics, and other sciences, robots have become adaptable and programmable to do several beneficial tasks and functions (Al Akaeel \& Al-Shammary, 2015). 
Vernado (2005) assured the importance of educational robot programs which have positive effects on developing students' cognitively, and on raising students' practical performance of building projects and solving problems. Norton, McRobbie, and Ginns (2007) conducted a study on preparatory school students. The study aimed at providing students with a developed learning environment, a modern curriculum and instructions that are compatible with the requirements of the 21 st century. The results of the study indicated that programing and building robots using Lego parts are considered effective tools to building attractive, pleasing learning environments which help in developing and enhancing problem solving strategies. Castledin and Chalmers (2011) conducted a study on primary school students. The study aimed at investigating the availability of using a robot as an effective tool to solving problems. An observation sheet for students' performance during the application of the study and study questionnaires, were used as tools to collect data in verifying the study hypotheses. Results showed that robotic activities helped students to consider different solutions to problems, and to take the right decisions such as choosing a different design and different program for each robot.

\subsection{Second: Scientific thinking skills}

Developing scientific thinking for students is one of the basic educational objectives for the Kingdom of Saudi Arabia, as scientific thinking helps students to make accurate decisions and integrates them into discussing issues, and solving problems in all fields.

\subsection{The concept of scientific thinking}

In the educational environment with all its elements as teachers and students, one can say that the role of the teacher is not limited to delivering the information, but it lies in facilitating the procurement of information for students and applying it in their lives. As a result, the concentration was not limited to acquiring the information, but to other objectives that help to develop several learner skills which require focusing on different scientific thinking skills. These skills help learners to distinguish between facts and deductions, to recognize causality and effect relationships, inference, predictions, and judging in light of sufficient evidence. Furthermore, different scientific thinking skills help learners to solve their daily problem in life outside classrooms (Ibrahim, 2004). Ghalyon (2002) identified the scientific thinking as, "one of mental activities that are used by humans to process the problems they face in their daily life, in research, and in investigating scientific problems objectively and systematically". Al-Sheikh and Abo Hamdan (2006) identified the scientific thinking as "a wide range of mental, kinetic, and psychological practices and operations, done by the individual, in a related logical organized form by which he/she reflects his/her skills in the three mentioned fields. These skills enable him/her to discover scientific knowledge and to justify it.

\subsection{The importance of scientific thinking}

Hortin, Ohlsen, and Newhose (1985) proved that scientific thinking and problem solving skills are the most important skills required for students to learn. In addition, Salama (2002) proved that the isolation of thinking separate from other aspects in life, is not a good process and consequently makes learning useless. Yager (2000a) focused on developing investigation and scientific research skills for students, in order to apply them in all life aspects. The individual needs scientific thinking skills to help him solve problems that face him in reaching meaningful knowledge, and to cope with the increasing developments of knowledge, which are difficult to face traditionally (Yager, 2000b).

Mason (1971) conducted a study on comparing the effects of both, the investigation method and the traditional method in science laboratory on developing scientific thinking for university students. Two groups were tested; an experimental group studied the laboratory using the investigation method and a control group studied using the traditional method. Utilizing instruments, the researcher could measure students' ability to understand information, scientific research skills and scientific attitudes. Results showed that the traditional method surpasses the investigation method in teaching information for two semesters, but after the third semester, 
the two methods became equal. Results also showed that the investigation method was more effective in acquiring students' scientific attitudes and scientific thinking skills, compared to the traditional method.

Al-Shahmany (2008) conducted a study aimed at measuring the effect of using formulating generalization strategy, according to the Helda Taba model, on academic achievement and on scientific thinking skills in Biology, for fifth grade students. The sample comprised 46 fifth grade students, randomly divided into two groups; an experimental group which included 24 students who studied using the formulating generalization strategy, and a control group which included 22 students who studied using traditional methods. Equivalence between groups was ensured by controlling variables such as, (age, intelligence, schemata, previous achievement in biology and scientific thinking skills). The researcher conducted the study for 7 weeks. The researcher built a 60-item MCQ achievement test and a 30-item scientific thinking skill test incorporating, (observation, organization, explanation, inference, generalization, prediction). The researcher used several statistical methods such as $\mathrm{T}$ test for unequal dependent groups, the Cooper agreement equation, and the Kuder- Richardson - 20 equations. Results showed that the experimental group which studied using the formulating generalization strategy surpassed the control group, which studied using the traditional method. Results also showed that there was a statistical difference between the mean scores of the pre-posttest of critical thinking for the experimental group, favoring the post test.

\subsection{Scientific thinking in this study}

Regarding issues based on mind and evidence drawn from experiments, is an objectively purposeful guided behavior towards studying problems with all their facts and dimensions, in order to reach explanations in which relations in the problem are shown (Al Khalili \& Younes, 1996, p. 527). Shawaheen (2005) identified scientific thinking as a series of mental activities required to apply methods of science and scientific thinking correctly. These mental activities are done by the brain when receiving a stimulus by one or more of five sensations, and these activities are an abstract concept, which includes non-visual and non-concrete activities (Shawaheen, 2005, p. 12). Operationally, in this study, scientific thinking is mental skills that require participant students to follow a sequence of scientific thinking skills, while receiving scientific information (designing and programming robots). These skills include; identification of the problem, suggesting best solutions, testing hypotheses, explanation, and generalization, and are measured by the score obtained by the student in the 34 multiple-Choice-question item test.

\section{Methodology}

The researcher used the quasi-experimental design. Participants were divided into two groups; Control and experimental. The Experimental Group is exposed to the dependent variable which is using the educational robot, where the control group was taught using the traditional way of teaching. Both groups were pretested and post-tested. The ultimate difference is that the experimental Group was taught using the educational robot (Designing and programming the educational robot NXT). The following table shows the procedures of study:

\section{Table 1}

Illustrations of experimental procedure for the current study

\begin{tabular}{llll}
\hline \multicolumn{1}{c}{ Group } & \multicolumn{1}{c}{ Pre-Test } & \multicolumn{1}{c}{ Experimental Procedure } & \multicolumn{1}{c}{ Post-Test } \\
\hline Experimental & Scientific Thinking Skills Measure & Teaching using the & Scientific Thinking Skills \\
& & scientific robot (NXT) & Measure \\
Control & & Teaching with & \\
& & conventional method & \\
\hline
\end{tabular}

\subsection{Community of the study}

Community of the study consisted of all students in the first grade at the 4th high school, in the Academic 
Effectiveness of educational robot in computer course in the development of scientific thinking skills year 2015-2016. The school was purposely chosen after coordination with the educational adviser for Computer. That school was specially chosen due to the availability of space and resources, in addition to the acceptance and cooperation of teachers and School administration, to perform the experiment of the study.

\subsection{Sample of the study}

The sample of the study consisted of a class of first grade students. The sample was purposely chosen. The first class was randomly chosen to be the experimental group, whereas the last class was chosen to represent the control group. The study sample consisted of 30 students.

\subsection{Instruments and materials of the study}

Materials of the study - The researcher used A Training program as an enrichment material to provide students with the necessary skills and information needed to deal with building and programming robots. The training program for designing and programming NXT robot was built according to the basics of building training programs, and went through the following steps:

Setting the objectives of the training program - The main objective of the training program for designing and programming robot was set based on Scientific thinking skills and objectives of Control and digital robot unit. The main objective is mastering Scientific searching skills through learning, in order to design and program the NXT robot. Subsidiary objectives of the program:

$>\quad$ Introduction to programming

$>$ Recognizing the components of NXT robot

$>\quad$ Installing NXT robot on personal computers

$>$ Mastering the stages of designing and programming robot

$>$ Programming different kinds of NXT robot engines.

$>\quad$ Dealing with NXT robot sensors

$>$ Effective dealing with the programming language Robot $\mathrm{C}$

$>\quad$ Writing a programming code that deals with different input devices (sensors and timers) and different output devices (engines and lamps) connected to NXT robot

$>\quad$ Building NXT robot

$>$ Encouraging students' participation and initiation in learning how to play the game.

Identifying scientific research skills included in the program - Identification of the problem, suggesting best solutions, verification of hypotheses, explanation and generalization.

Identification of the target group - First grade secondary school students.

Choosing the content and the organization the program - The program included three main axes, (introduction to robot, stage of designing robot, stage of programming robot).

Setting the methods of applying the program - More than one instruction was adopted during the application of the program. Integration of these instructions was ensured. In addition, these instructions were compatible with objectives and contents. These instructions included lectures, discussions, workshops, self-learning, cooperative learning and presentations.

Choosing the educational aids for applying the program:

$>$ Computers

$>$ Projectors

$>\quad$ Flash memories

$>$ Educational case for NXT robot 
Training was held in the 4th high school classrooms as enrichment sessions for Control and digital robot unit, during computer subject time, for the first-grade secondary school students, from April 2, 2016 to April 4, 2016.

\subsection{Instrument of the study}

The researcher prepared a scale to measure Scientific thinking skills (identification of the problem, suggesting best solutions, verification of hypotheses, explanation, and generalization). Reliability of the scale was $70.3 \%$. The difficulty index for the scale was approximately 0.35 . The Discrimination Power of items ranged between 0.33 and 0.62 . The Scientific thinking skills test was built according to certain steps. Because of the unavailability of scientific thinking skills that matched the nature of both first-grade secondary school students and the subject, the researcher had to build a test to serve the objectives of the study. After reviewing literature related to scientific thinking, the researcher completed the following steps:

Stating test items - After reviewing Scientific thinking scales in some resources such as (Shawaheen, 2005) and (Alshahmany, 2008), the researcher prepared the final version of items of Scientific thinking skills. The test consisted of $34 \mathrm{MCQs}$ divided into five sub-skills (identification of the problem, suggesting best solutions, verifications of hypotheses, explanation, and generalization). The test was administered by a group of experts and specialists in computers and methodology for evaluation.

Stating testing instructions - Test instructions were written for students in order to show them how to answer each item and avoid losing scores. In addition, a score was assigned to each item in the test. Furthermore, a time limit was attached, within which students had to answer the test.

Pilot study - The test was administered to a pilot sample consisted of 60 first grade secondary school students at the fourth high school, to ensure the clarity of items, and test instructions, in addition to diagnosing vague items, in order to rephrase them and set the appropriate time for the test.

Scoring the test - After the application of the pilot study, responses of the students were evaluated by giving one grade for the correct response and zero for an incorrect or missing response.

Validity of the test - The validity of the test is one of the main characteristics of the study instrument. The instrument is described as valid when it actually measures exactly what it was designed for Simmons and Lehmann (2012). Thus, the researcher ensured the validity of the test as follows:

$>$ Face validity - To verify the validity of the test, the researcher depended on a jury to state their opinions on how far the items measure the intended outcomes, the clarity of items, figures and pictures, and how consistent the alternatives are. Opinions of the jury were considered and used to modify some items.

$>$ Construct validity - The construct validity of the test was ensured by using the difficulty index and discrimination power

$>\quad$ Difficulty index - The difficulty index for each item was calculated using difficulty formula, and found to be $(0.35-0.65)$ and this value was consistent with the value of good classroom tests, which ranges between $20 \%$ and $80 \%$ (Al-Zaher et al., 2002, p. 129).

$>$ Discrimination power - Discrimination power means the ability to discriminate between a higher achiever and low achiever on the test (Al-Zaher et al., 2002 p. 129). By using the discrimination power formula, the Discrimination power of items ranged between 0.33 and 0.62. Ebel indicates that the good item must have discrimination power of $30 \%$ and above (Al-Emam \& Ajeel, 1990, p. 117). 
Effectiveness of educational robot in computer course in the development of scientific thinking skills

Reliability of the test - The reliability of the test was calculated using Kuder- Richardson - 20 (Rodny, 1985, p. 165) and found to be (0.73). Therefore, the test in its final form consisted of 34 items to measure scientific thinking skills for the first-grade secondary school students.

\subsection{Implementation of the study}

The study was implemented according to the following:

Choosing the study sample - Two classrooms of first grade secondary school students represented the experimental and control group.

Equivalence of two groups - Equivalence of two groups was ensured by using the pre-test of scientific thinking skills before the implementation of the study.

Pre-test procedures - The pre-test of scientific thinking skills were administered to all experimental and control groups, on Wednesday March 29, 2016.

Study implementation procedures - A 12-hour training program entitled, (designing and programing NXT robot) was implemented between Sunday May 1, 2016 and Wednesday May 4, 2016.

The experimental application of educational robot tracked the following steps:

$>$ Teaching Control group students the robot and digital control unit in the computer subject, using the traditional way of teaching

$>\quad$ Teaching experimental group students, the robot and digital control unit in the computer subject using the educational robot.

The researcher met the experimental Group students before the application in order to fully explain the objectives of the training program. Introduction to programming:

$>$ Recognizing the components of NXT robot

$>\quad$ Installing NXT robot on personal computers

$>$ Mastering the stages of designing and programming robot

$>$ Programming different kinds of NXT robot engines

$>\quad$ Dealing with NXT robot sensors

$>$ Effective dealing with the programming language Robot $\mathrm{C}$

$>\quad$ Writing a programming code that deals with different input devices (sensors and timers) and different output devices (engines and lamps) connected to

$>\quad$ NXT robot

$>$ Building NXT robot

$>$ Encouraging students' participation and initiation in order to learn how to play the game

$>$ Teaching experimental Group Students using the blended learning method, which blends the traditional way to using the educational robot NXT. The researcher supervised and followed up on how students build, design and program the robot, in addition to scientific thinking skills.

The following are photos for designing and programing NXT robot (figures 1 to 3):

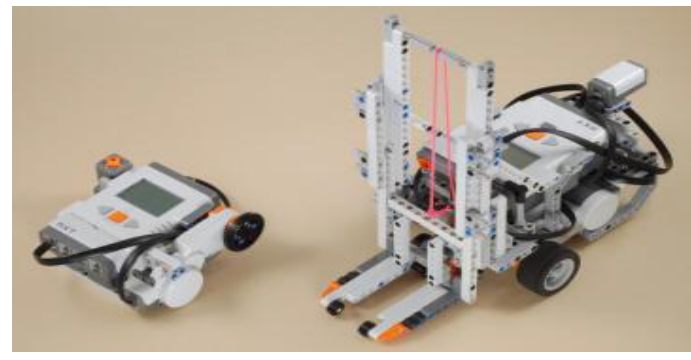

Figure 1. Robots 


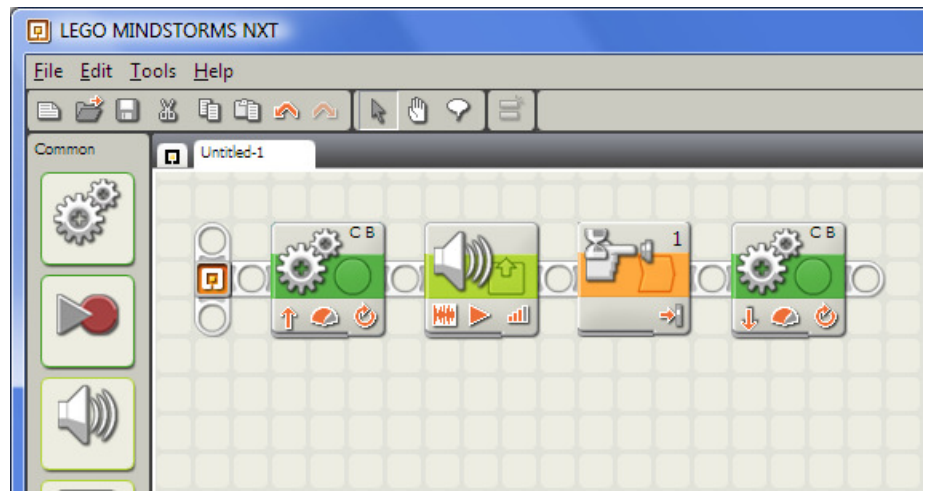

Figure 2. Software screenshot

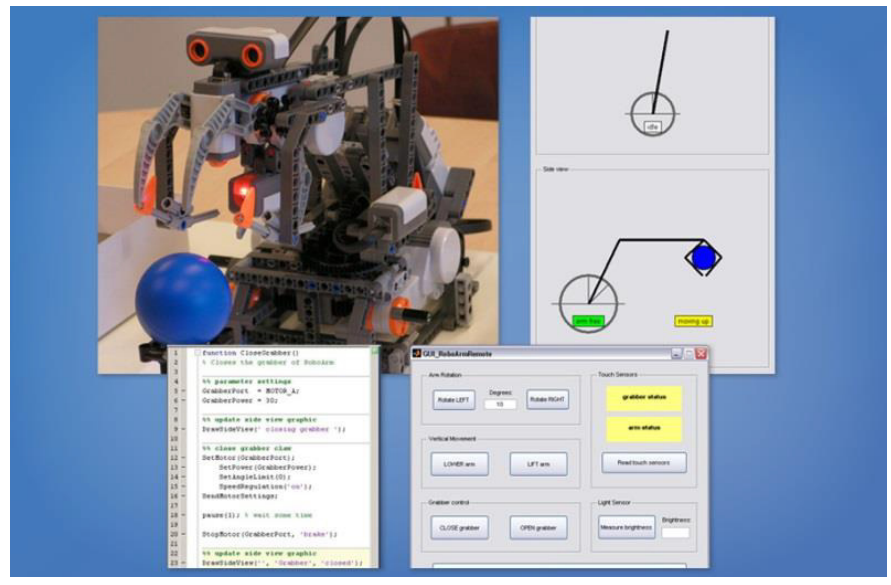

Figure 3. Sample lesson

Post-test procedures - After teaching experimental group students with educational robot NXT, and control group students in the traditional way, the following steps were taken. Application of the post-test of scientific thinking skills on both groups: April 28, 2016.

\section{Analysis of the Study Results}

The researcher built a test for scientific thinking skills in order to measure the level of scientific thinking for the first grade secondary school students in computer, for both the experimental and control group, before and after the application of the experiment (Teaching using the educational robot NXT) in the following skills, (identification of the problem, suggesting best solutions, verification of hypotheses, explanation, generalization). The difficulty index, discrimination power and reliability coefficient was calculated. The total score for the test was 34. Data was processed using a statistical package for social sciences SPSS in order to calculate T test for two independent means, to verify the Study hypotheses. This section tackles the results obtained after the application of the study instruments (scientific thinking skills test).

\subsection{First: Verification of the groups' equivalence (experimental and control) and their validity to conduct the experiment.}

To ascertain if there are statistical differences between experimental and control groups in Scientific thinking skills, the researcher used t-test for dependent groups, to test statistical differences between the mean score of the experimental and control group the pre-test Scientific thinking skills (table 2). 
Effectiveness of educational robot in computer course in the development of scientific thinking skills

Table 2

T-test results for Scientific thinking skills pretest for the experimental and the control group

\begin{tabular}{|c|c|c|c|c|c|c|c|}
\hline \multirow{2}{*}{ Group } & \multirow{2}{*}{$\mathrm{N}$} & \multirow{2}{*}{ M } & \multirow{2}{*}{$\mathrm{SD}$} & \multirow{2}{*}{$\mathrm{DF}$} & \multicolumn{2}{|c|}{$\mathrm{T}$} & \multirow{2}{*}{$\mathrm{Sig}$} \\
\hline & & & & & calculated & table & \\
\hline Exp. & 30 & 25 & 2.89 & \multirow{2}{*}{58} & \multirow{2}{*}{1.44} & \multirow{2}{*}{1.99} & 0.05 \\
\hline Cont. & 30 & 24 & 2.78 & & & & Not Sig \\
\hline
\end{tabular}

Results showed that there were no statistical differences at the level 0.05 and degree of freedom 58 in Scientific thinking skills test, and that guarantees the equivalence of the two groups (experimental and control) and their validity for the application of the experiment.

\subsection{Second: Answering study questions}

Verification of null hypothesis which states that there are no statistical differences at 0.05 level in the post-test of scientific thinking skills between the mean scores of the experimental group, which studied using educational robot and the control group which studied using traditional way in computer subject, after controlling the pre-test. To verify that hypothesis, the researcher used independent T-test to find the differences in the post-test of scientific thinking skills between the mean scores of the experimental group and the control group (Table 3 ).

\section{Table 3}

Independent T test for post-test of scientific thinking skills for experimental and control groups

\begin{tabular}{|c|c|c|c|c|c|c|c|c|}
\hline \multirow{2}{*}{ Group } & \multirow{2}{*}{$\mathrm{N}$} & \multirow{2}{*}{ M } & \multirow{2}{*}{ SD } & \multirow{2}{*}{ DF } & \multicolumn{2}{|c|}{$\mathrm{T}$} & \multirow{2}{*}{ Sig } & \multirow{2}{*}{$\eta^{2}$} \\
\hline & & & & & calculated & table & & \\
\hline Exp. & 30 & 28 & 3.73 & \multirow{2}{*}{58} & \multirow{2}{*}{6.97} & \multirow{2}{*}{1.99} & 0.05 & \multirow{2}{*}{0.47} \\
\hline Cont. & 30 & 25 & 3.53 & & & & Not Sig & \\
\hline
\end{tabular}

Table 3 shows that calculated $\mathrm{T}$ for the difference between mean scores of post-test of the scientific thinking skills is 6.97 and is significant at 0.05 level, which indicates the effectiveness of the experimental factor (teaching using the educational robot) in developing scientific thinking skills for the first grade secondary school students. The effect size $\eta^{2}$ is 0.47 , and this value, according to the Cohen scale, refers to a large effect for experimental treatment (teaching using the educational robot) on scores of scientific thinking test. Based on that result, the null hypothesis is rejected and the alternate hypothesis is accepted; (There are statistical differences at 0.05 in the post-test of scientific thinking skills between the mean scores of the experimental group which studied using the educational robot, and the control group which studied using the traditional method in computer subject, after controlling the pre-test.

The researcher ascribed the supremacy of the experimental group over the control group to the following:

$>$ Learning by using the educational robot is an active mental process which concentrates on the positivity of the learners and their activities. As the information is not directly introduced to students, students are practically directed to obtain information through the process of building, designing, and programing robots. In addition to the variety of solutions to problems, the teachers design, apply and collect evidence regarding the problem. The lesson which is based on the enrichment use of educational robot, enables the learner to practice most scientific thinking skills such as observations, predictions, inferences, experimentation, hypothesizing, etc., which helps students to acquire critical thinking skills.

$>\quad$ Teaching by using an educational robot helps students to be autonomous learners, and to acquire leadership and communication skills within the group. 


\section{Recommendations}

In light of the results, the following recommendations are presented:

$>$ Encouraging computer teachers to use the educational robot, which enables students to employ mental skills, and to direct thinking processes towards creativity

$>$ Conducting training workshops for teachers in building, designing, and programing robot

$>\quad$ Satisfying the needs of smart and talented students by preparing special enrichment programs for them

$>$ Integrating the use of the educational robot in the educational curriculum.

\subsection{Suggestions}

The researcher suggests conducting the following researches:

$>\quad$ The effectiveness of using the educational robot in developing achievement and thinking skills in scientific branches, such as physics and mathematics

$>\quad$ The effectiveness of using the educational robot in developing special needs skills in all basic education levels, in Computer and Mathematics.

\section{References}

Abo-Gado, S. M. (2007). Teaching thinking [In Arabic]. Amman, Jordan: Maysara House.

Al-Akail, W. (2014). The effect of robot program in developing program solving and motivation for superior preparatory school students in Saudi Arabia [In Arabic] (Master thesis). Faculty of higher education, Arab Gulf University, Bahrain.

Al-Atoom, A., Al-Jarrah, A., \& Bisharah, M. (2009). Developing thinking skills [In Arabic] (2nd ed.). Maysara Publications House, Amman, Jordan (Arabic).

Al-Emam, M., \& Ajeeli, S. (1990). Evaluation and assessment in research [In Arabic]. Wisdom Publication House, Baghdad, Iraq.

Al-Far, E. (2002). Computer pedagogic and challenges of 21st centuries [In Arabic]. Cairo: Arab Thought House.

Al-Habahba, B. (2010). Scholastic robot project. Electronic learning and pedagogic challenges magazine [In Arabic] (2nd ed., pp. 24-26). Rania Al-Abadallah Center for Education Technology.

Al-Haidary, M. (2007). The effect Wooderz model in science achievement and mental skills for first grade students [In Arabic] (Unpublished Master thesis). Faculty of education, Ibn El-Haytham university, Bagdad.

Al-Hela, M. M. (2009). Classroom teaching skills [In Arabic] (3rd ed.). Amman, Jordan: Maysara House.

Al-Kayem, K. (2007). Scientific research curriculum and methodologies in humanities [In Arabic]. Bagdad, Iraq: National Library.

Al-Shahmany, A. (2008). Effect of generalization strategy according to Helda Taba in biology achievement and scientific thinking skills for the fifth-grade students [In Arabic] (Unpublished Master thesis). Faculty of education, Ibn Al-Haytham, Bagdad University.

Al-Tety, M. H. (2007). Developing creative thinking [In Arabic] (3rd ed.). Amman, Jordan: Maysara House.

Al-Zaher, Z., et al. (2002). Fundamentals of evaluation and assessment in education [In Arabic]. Amman, Jordan: Culture House.

Bader, B. M. (2006). The effect of metacognitive strategies on developing thinking methods for mathematic section students, faculty of education, Mecca [In Arabic] (12th ed., Vol. 41). Arab Center for Education and Development.

Castledine, A., \& Chalmers, C. (2011). LEGO robotics: An authentic problem solving tool? Design and Technology Education: An International Journal, 16(3), 19-27.

Davis, I. (1973). Competency based learning: Technology, management and design. New York: McGraw-Hill. 
Effectiveness of educational robot in computer course in the development of scientific thinking skills

Ghalyoon, A. (2002). The effectiveness of using Osbel model in teaching chemistry for developing scientific thinking skill [In Arabic] (Unpublished Master thesis). Cairo University.

Judy, S., \& Goldberg. D. (2001). For the learner's sake: Brain-based instruction for the 21st century. Arizona: Zephy Press.

Kousta, A., et.al. (1998). Education for developing thinking [In Arabic] (Translation of Safaa El-Assar). Cairo: Qebaa House.

Livingston, J. (1996) Effects of metacognition instruction on strategy use of college students. Buffalo: University of New York.

Norton, S., J., McRobbie, C. J., \& Ginns, I. S. (2007). Problem solving in a middle school robotics design. Research in Science Education, 37(3), 261-277. https://doi.org/10.1007/s11165-006-9025-6

Salama, A. (2002). Methodologies and their role in thinking [In Arabic]. Amman, Jordan.

Shawaheen, B. (2009). Developing creative thinking in science and mathematics using scientific imagination [In Arabic]. Amman: Maysara House.

Simmons, C., \& Lehmann, P. (2012). Tools for strengths-based assessment and evaluation. New York: Springer Publishing Company.

Stanley, J., \& Hopkins, K. (1972). Education and psychology measurement and evaluation. New York: Prentice Hall.

Verner, I. M., \& Hershko, E. (2003). School graduation projection root design: A case study of team learning. https://doi.org/10.21061/jte.v14i2.a.4

Yager, R. (2000a). A vision for what science education should be like for the 25 years of a new millennium.

School Science and Mathematics, 100(6), 327-341. https://doi.org/10.1111/j.1949-8594.2000.tb17327.x

Yager, R. (2000b). Problem solving skills for school personal and students. Journal of School Improvement, $1(2)$.

Zayton, A. (2005). Science teaching methodology [In Arabic]. Amman, Jordan: Al-Mashraq house. 
Al-Mohammadi, N. 